\title{
Biomedical
}

Research \& Therapy

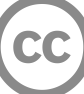

ISSN: $2198-4093$

www.bmrat.org

Original Research

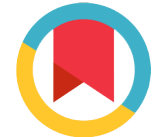

Check for updates
*For correspondence:

salman.khazaei61@gmail.com

Competing interests: The authors declare that no competing interests exist.

Received: 06 March 2017

Accepted: 04 June 2017

Published: 27 June 2017

Copyright The Author(s) 2017. This article is published with open access by BioMedPress (BMP).

This article is distributed under the terms of the Creative Commons Attribution License (CC-BY 4.0)

which permits any use,

distribution, and reproduction in any medium, provided the original author(s) and the source are credited.

\section{Estimates of global HIV/AIDS mortality, prevalence and incidence rates, and their association with the Human Development Index}

\section{Kamyar Mansori ${ }^{1,2}$, Erfan Ayubi ${ }^{3}$, Fatemeh Khosravi Shadmani ${ }^{4}$, Shiva Mansouri Hanis ${ }^{5}$, Somayeh Khazaei ${ }^{6}$, Mohadeseh Sani ${ }^{7}$, Yousef Moradi $^{8}$, Salman Khazaei9,10,*, Abolfazl Mohammadbeigi ${ }^{11}$}

\footnotetext{
${ }^{1}$ Social Development \& Health Promotion Research Center, Gonabad University of Medical Sciences, Gonabad, Iran

${ }^{2}$ Department of Epidemiology, School of Public Health, Iran University of Medical Sciences, Tehran, Iran

${ }^{3}$ Department of Epidemiology, School of Public Health, Shahid Beheshti University of Medical Sciences, Tehran, Iran

${ }^{4}$ Modeling in Health Research Center, Institute for Futures Studies in Health, Kerman University of Medical Sciences, Kerman, Iran

${ }^{5}$ School of Public Health, Dezful University of Medical Sciences, Dezful, Iran

${ }^{6}$ Rafsanjan University of Medical Sciences, Rafsanjan, Iran

${ }^{7}$ School of Medicine, Zabol University of Medical Sciences, Zabol, Iran

${ }^{8}$ Pars Advanced and Minimally Invasive Manners Research Center, Pars Hospital, Iran University of Medical Science, Tehran, Iran

${ }^{9}$ Department of Epidemiology, School of Public Health, Hamadan University of Medical Sciences, Hamadan, Iran

${ }^{10}$ Department of Epidemiology and Biostatistics, School of Public Health, Tehran University of Medical Sciences, Tehran, Iran

${ }^{11}$ Research Center of Gastroenterology and Hepatology, Oom University of Medical Sciences, Qom, Iran
}

\section{Abstract}

Background: HIV/AIDS is one of greatest global public health concerns today due to the high incidence, prevalence and mortality rates. The aim of this research was investigate and estimate the global HIV/AIDS mortality, prevalence and incidence rates, and explore their associations with the Human Development Index. 
Methods: The global age-standardized rates of mortality, prevalence and incidence of HIV/AIDS were obtained from the UNAIDS for different countries in 2015. The human development indexes (HDIs) were obtained from the World Bank database. The surveyed countries were divided into four groups according to the HDI distribution. The Spearman correlation coefficient and one-way ANOVA test were used for assessing the association of HIV/ AIDS indicators and HDI. Results: The highest rates of HIV/AIDS prevalence and incidence, and associated mortality in East and Southern Africa countries were $51.73 \%, 46.33 \%$ and $42.3 \%$, respectively. Moreover, the highest and lowest global age-standardized rates of incidence and prevalence of HIV/AIDS was seen in adults ranging from 15-49 years of age for both low and high HDI countries. The prevalence and incidence rates of HIV/AIDS each had an inverse correlation with HDI and its four indicators (life expectancy at birth, mean years of schooling, expected years of schooling, and GNI per capita). Conclusion: Less developed countries with lower HDI show greater severity of the AIDS epidemic. Thus, it is essential to pay more attention to HIV/AIDS control and prevention programs in these countries.

\section{Keywords}

HDI, HIV/AIDS, Human development index, Incidence, Mortality, Prevalence

\section{Introduction}

Sustainable Development Goals (SDGs) is an UN plan for achieving a better future for all people over the next 15 years (2015-2030). It consists of 17 goals and 169 targets. Among the goals, the third one to to ensure healthy lives and promote well-being for all ages. With regard to this, one of the critical targets is to end the epidemics of AIDS by the year 2030.

UNAIDS has estimated that 36.7 million people globally are living with HIV. In 2015, approximately 2.1 million people became newly infected with HIV and 1.1 million people died from AIDS-related illnesses (UNADIS, 2016). HIV/AIDS and the related illnesses represented $2.44 \%$ of global deaths (Institute for Health Metrics and Evaluation (IHME), 2015). HIV/AIDS is the $5^{\text {th }}$ leading cause of DALY in recent years (Murray et al., 2013). However, the burden of epidemic HIV/AIDS varies considerably in different regions and geographical divisions (WHO, 2016).

The difference among countries depends on various factors. The most notable factors or influences are wealth, education, poverty, immigration, addiction, and sexually transmitting diseases (Piot et al., 2007; Yancy et al., 2017). The Human Development Index (HDI) is associated with the development of societies; it is composed of the mean scores of the three indexes of life expectancy at the time of birth, gross national product (GNP) per capita, and education. Some of the 
studies have reported that HDI affects HIV (Boulogne et al., 2017; Boutayeb, 2009; Colecraft, 2008; de Freitas Souza et al., 2017).

This present study aims to investigate the correlation of HIV related death incidence and HDI to understand how HIV/AIDS affect global development. Understanding this helps provide a basis for more purposeful medical and preventive measures which may be implemented.

\section{Materials-Methods}

The present study is an epidemiological study which utilized the global dataset of HIV/AIDS (this global dataset includes incidence, prevalence and mortality rates of HIV/AIDS worldwide).

\section{Global HIV/AIDS data}

The global age-standardized rates of mortality, prevalence and incidence of HIV/ AIDS were obtained from the UNAIDS for different countries in 2015 (UNAIDS, 2016a). In fact, UNAIDS produces a biannual estimation of these indicators for HIV/AIDS for all countries (UNAIDS, 2016b).

\section{HDI}

The HDI data and its components, including life expectancy at birth, mean years of schooling, expected years of schooling and gross national income (GNI) per capita, were taken from the World Bank database from 2015 (Ledwidge et al., 2013). The HDI index has a range between 0 to 1 ; values closer to 1 reflect a higher HDI. In general, countries in the database are divided into four categories according to the value of $\mathrm{HDI}$. The categories are as follows: very high $(\mathrm{HDI} \geq 0.8)$, high $(0.7 \leq \mathrm{HDI} \leq 0.799)$, medium $(0.55 \leq \mathrm{HDI} \leq 0.699)$, and low (HDI<0.55) (Ledwidge et al., 2013).

\section{Statistical analysis}

Descriptive statistics such as charts and tables were used to present data. Continual assessment of changes in trend of global incidence, prevalence and mortality of HIV/HIDS occurred during the time period of 2000-2015. The Cochran-Armitage test was used. Comparisons among HDI- categorized countries (very high, high, medium, and low) for HIV/AIDS incidence and prevalence was done with one-way ANOVA. Spearman correlation coefficient was used to evaluate the relationship between the prevalence of HIV/AIDS and incidence to the national HDI.

The significant level was set as $p<0.05$. Data were analyzed using Stata computer software version 12 (StataCorp, College Station, TX, USA). 


\section{Results}

Overall 161 countries had epidemiologic data on HIV/AIDS. HDI were available and was included in the study. Figure 1 shows changes in the trend of global incidence, prevalence and mortality of HIV/HIDS during the time periods of 2000-2015. Accordingly, the global incidence of HIV/AIDS demonstrate a downward trend in this period for the children ( 0.49 million in 2000 as compared to 0.15 million in 2015) and adults (2.7 million in 2000 as compared to 1.9 million in 2015). Note that the overall $P_{\text {trend }}<0.001$. A similar situation existed with regard to the mortality rate (1.3 million in 2000 as compared to 1 million in 2015 for adults, and 0.24 million in 2000 as compared to 0.11 million in 2015 for children, respectively). The overall $P_{\text {trend }}=0.01$. However, for prevalence, unlike the data for the children (a relatively stable trend), the adult data increased ( 27.2 million in 2000 as compared to 34.9 million in 2015). Overall. $P_{\text {trend }}<0.001$.

As shown in Table 1 , the highest prevalence rate, incidence rate and mortality of HIV/AIDS in 2015 belonged to East and Southern Africa countries, with 51.73\%, 46.33\% and 42.3\%, respectively. Middle East and North Africa countries had the lowest rates of mentioned indicators, with $0.63 \%, 1.01 \%$ and $1.08 \%$, respectively.

Table 1. Incidence, prevalence and mortality rate of HIV/AIDS in different UN region, 2015

\begin{tabular}{|c|c|c|c|c|c|c|}
\hline \multirow{2}{*}{ UN Region } & \multicolumn{2}{|c|}{ People living with HIV } & \multicolumn{2}{|c|}{ New HIV infections } & \multicolumn{2}{|c|}{ AIDS-related deaths } \\
\hline & $\begin{array}{l}\text { Estimated } \\
\text { frequency }\end{array}$ & Percentage & $\begin{array}{l}\text { Estimated } \\
\text { frequency }\end{array}$ & Percentage & $\begin{array}{l}\text { Estimated } \\
\text { frequency }\end{array}$ & Percentage \\
\hline Asia and the Pacific & $5,100,000$ & 13.89 & 300,000 & 14.48 & 180,000 & 16.20 \\
\hline $\begin{array}{l}\text { Eastern Europe and Central } \\
\text { Asia }\end{array}$ & $1,500,000$ & 4.08 & 190,000 & 9.17 & 47,000 & 4.23 \\
\hline East and Southern Africa & $19,000,000$ & 51.73 & 960,000 & 46.33 & 470,000 & 42.30 \\
\hline $\begin{array}{l}\text { Latin America and the } \\
\text { Caribbean }\end{array}$ & $2,000,000$ & 5.45 & 100,000 & 4.83 & 50,000 & 4.50 \\
\hline Middle East and North Africa & 230,000 & 0.63 & 21,000 & 1.01 & 12,000 & 1.08 \\
\hline West and Central Africa & $6,500,000$ & 17.70 & 410,000 & 19.79 & 330,000 & 29.70 \\
\hline $\begin{array}{l}\text { Western and Central Europe } \\
\text { and North America }\end{array}$ & $2,400,000$ & 6.53 & 91,000 & 4.39 & 22,000 & 1.98 \\
\hline Total & $36,730,000$ & 100 & $2,072,000$ & 100 & $1,111,000$ & 100 \\
\hline
\end{tabular}



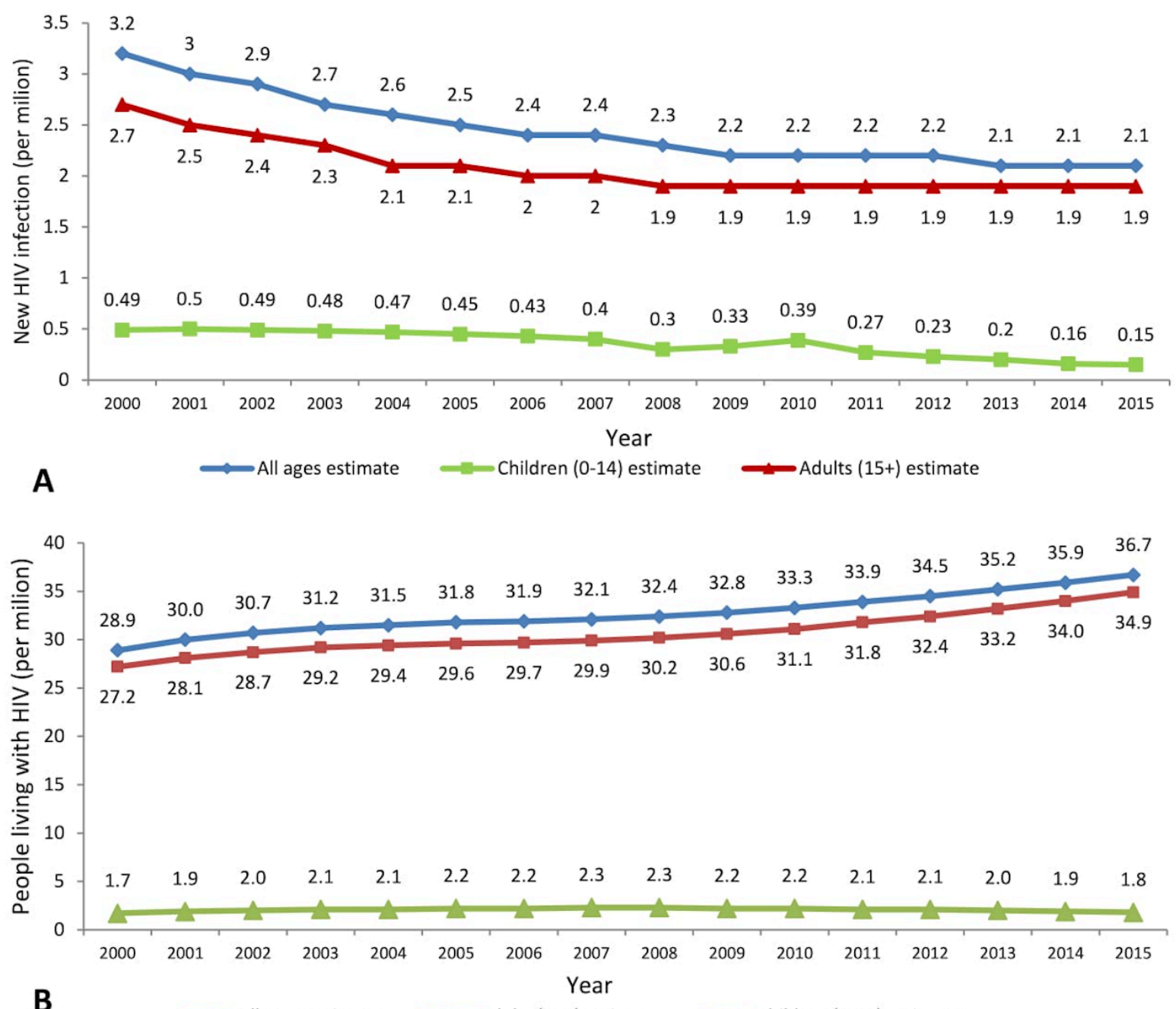

B

$\longrightarrow$ All ages estimate $\quad \longrightarrow$ Adults (15+) estimate $\longrightarrow$ Children (0-14) estimate

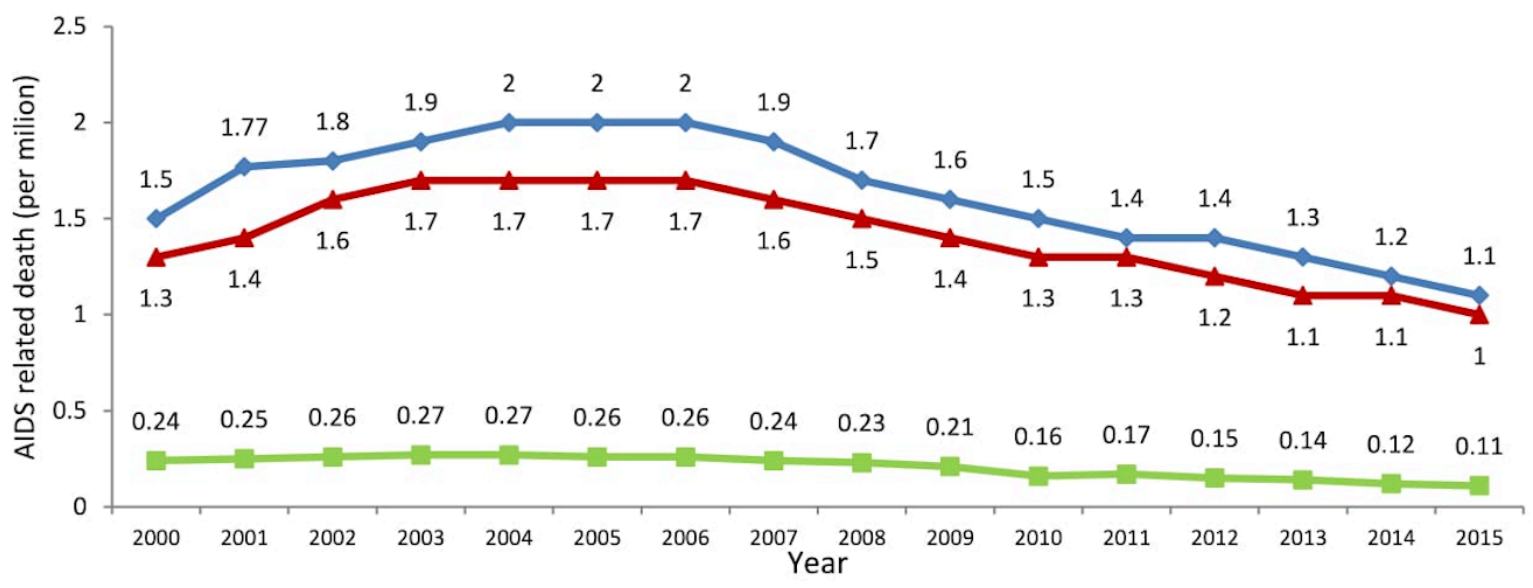

C $\longrightarrow$ All ages estimate $\quad \longrightarrow$ Children (0-14) estimate $\quad$ Adults (15+) estimate

Figure 1. Global trend of $(A)$ incidence, $(B)$ prevalence and $(C)$ mortality rate for HIV/AIDS by age group (2000-2015). 
Table 2. Prevalence, Incidence \& Mortality (\%) of HIV/AIDS in different HDI regions, 2015

\begin{tabular}{|c|c|c|c|c|c|c|}
\hline \multicolumn{2}{|c|}{ Index } & \multirow{2}{*}{$\begin{array}{c}\begin{array}{c}\text { Very High } \\
\text { Human } \\
\text { Development }\end{array} \\
0.012\end{array}$} & \multirow{2}{*}{$\begin{array}{c}\begin{array}{c}\text { High Human } \\
\text { Development }\end{array} \\
0.018\end{array}$} & \multirow{2}{*}{$\begin{array}{c}\begin{array}{c}\text { Medium } \\
\text { Human } \\
\text { Development }\end{array} \\
0.14\end{array}$} & \multirow{2}{*}{$\begin{array}{c}\begin{array}{c}\text { Low Human } \\
\text { Development }\end{array} \\
0.25\end{array}$} & \multirow{2}{*}{$\begin{array}{c}\text { P-value } \\
\text { (F-test) } \\
0.32\end{array}$} \\
\hline IR among & Mean & & & & & \\
\hline years & SE & 0.003 & 0.004 & 0.04 & 0.08 & \\
\hline \multirow{2}{*}{$\begin{array}{l}\text { PR among } \\
\text { adults15-49 } \\
\text { years }\end{array}$} & Mean & 0.22 & 0.23 & 2.37 & 3.73 & \multirow{2}{*}{0.31} \\
\hline & SE & 0.03 & 0.07 & 0.67 & 1 & \\
\hline
\end{tabular}

IR: Incidence rate, PR: Prevalence rate

According to Table 2, the highest age-standardized incidence rate and prevalence rate of HIV/AIDS among adults 15-49 years was seen in low human development region. The lowest rate were seen in very high HDI countries.

The correlation between $\mathrm{HDI}$ and its components with epidemiologic indicators of HIV/AIDS were shown in Table 3. Accordingly, the sign of the Spearman correlation indicates that $\mathrm{HDI}$ and its components have the inverse correlation with HIV/AIDS incidence and prevalence. From the aforementioned epidemiologic parameters, the prevalence among young women (15-24 years) had the strongest relation with the HDI $(r=-0.61, P<0.05)$. Life expectancy at birth ( $r=-0.72, P<0.05)$, mean years of schooling $(r=-0.45, P<0.05)$ and gross national income per capita $(r=-0.49, P<0.05)$ were quantified.

Table 3. Correlation between Human Development Index and its components, and HIV/AIDS epidemiologic parameters

\begin{tabular}{|c|c|c|c|c|}
\hline \multirow[b]{2}{*}{ Variable } & \multirow[b]{2}{*}{ Incidence } & \multicolumn{3}{|c|}{ Prevalence } \\
\hline & & $\begin{array}{l}\text { Young women } \\
15-24 \text { years }\end{array}$ & $\begin{array}{l}\text { Young men } \\
15-24 \text { years }\end{array}$ & $\begin{array}{c}\text { Adults } \\
15-49 \text { years }\end{array}$ \\
\hline HDI & -0.42 & -0.61 & -0.45 & -0.53 \\
\hline Life expectancy at birth, year & -0.61 & -0.72 & -0.54 & -0.63 \\
\hline Mean years of schooling & -0.25 & -0.45 & -0.3 & -0.36 \\
\hline Expected years of schooling & -0.34 & -0.38 & -0.32 & -0.41 \\
\hline $\begin{array}{l}\text { Gross national income per } \\
\text { capita, \$ }\end{array}$ & -0.35 & -0.49 & -0.38 & -0.43 \\
\hline
\end{tabular}




\section{Discussion}

In this study, we investigate the association between global age-standardized rates of mortality, prevalence, and incidence of HIV/AIDS obtained from the UNAIDS with HDI and its components, including life expectancy at birth, mean years of schooling, expected years of schooling, and gross national income (GNI) per capita, taken from the World Bank database of 2015.

The results of this study showed the highest and lowest rates of prevalence, incidence and mortality of HIV/AIDS were related to East and Southern Africa countries \& Middle East and North Africa countries, respectively. Also, the highest and lowest of the global age-standardized rates of incidence and prevalence of HIV/AIDS was observed among adults 15-49 years- in low and very high HDI countries, respectively. Prevalence and incidence rates of HIV/ AIDS had inverse correlations with national HDI and its four indicators (life expectancy at birth, mean years of schooling, expected years of schooling, and GNI per capita).

In our study, the highest rates of prevalence, incidence, and mortality of HIV/ AIDS were related to East and Southern Africa countries, consistent with reports and studies conducted in this filed (Akeroyd, 1994; Arndt and Lewis, 2000; HIV/ AIDS, 2010). There are several factors that account for Africa's high infection rate. The first and most common reason is the high rate of poverty and economic disparity. Another important factor is lack of education since education plays a vital role on both HIV/AIDS awareness, as well as support for those affected by the illness. Also, other factors include the high rate of prostitution, polygamy and promiscuity, sexual violence, rapid urbanization and mobilization. Each plays a major role on high infection rates and the spread of the epidemic in East and Southern Africa countries (Arndt and Lewis, 2000; De Cock et al., 2002; Whiteside, 2002). Thus, preventive interventions may be effective regardless of the impact of the factors on those continents.

Moreover, in our study the highest and lowest rates of age-standardized incidence and prevalence of HIV/AIDS were observed among adults (15-49 years old) in low $\mathrm{HDI}$ and very high $\mathrm{HDI}$ countries. The results are consistent with studies conducted in this filed (Ärnlöv, 2016; Gesesew et al., 2016; Lou et al., 2014). The results are logical due to the prevalence of high-risk behaviors related to HIV/AIDS (e.g. injecting drug use and unprotected sexual activity) in adults aged 15-49 years; additionally, it should be noted that the interventional programs of prevention should be focused on this age group (15-49 years).

The prevalence and incidence rates of HIV/AIDS had inverse correlation with HDI and its four indicators, including life expectancy at birth, mean years of schooling, expected years of schooling, and GNI per capita. Indeed, prevalence and incidence rates were higher in countries with lower HDI compared to those with higher HDI. These results are also consistent with other similar studies which have been carried out in this field (Ärnlöv, 2016; Gesesew et al., 2016; HIV/AIDS, 
2010; Lou et al., 2014). Many studies have shown that HIV/AIDS has a significant effect on health and that good indicators include mortality rates and life expectancy. For example, two studies in the field of global inequality of life expectancy have shown that the 6 years of the difference in life expectancy between Africa and North America is related to AIDS (Dorling D; Wong et al., 2017).

Moreover, in this study the mean years of schooling had an inverse correlation with prevalence and incidence rates of HIV/AIDS. Education is an important component of $\mathrm{HDI}$ and it is necessary to include that parameter, especially in countries with low- and medium-income. In most African countries, HIV/AIDS has shown an inverse association with primary education, especially in girls (Wong et al., 2017). In these countries the death of parents due to AIDS is frequent; the issue of family economic situations will aggravate and also will increase the number of children dismissed from school (Boulogne et al., 2017; Lou et al., 2014). On the other hand, an important factor that has a major role in prevention of HIV transmission is mean years of schooling. This factor is essential in interventional programs of prevention.

Various studies have shown that HIV/AIDS is a disease of poverty. More than $60 \%$ of people living with HIV/AIDS in the world have been deployed in subSaharan Africa. Indeed, the countries of this region have low economic growth and cannot pay the cost of high antiretroviral therapy nor prevention programs (Billebeau et al., 2017). Hence, poverty makes people susceptible to HIV/AIDS. Also, in this study the negative correlation between GNI per capita and HIV/ AIDS prevalence, and incidences rates were verified.

\section{Conclusion}

The results of our study revealed an inverse relationship between the global age-standardized rates of mortality, prevalence, and incidence of HIV/AIDS with its components including life expectancy, years of schooling, and GNI per capita. Less developed countries, as measured by HDI. In other words, the less developed countries with lower HDI have greater severity of the AIDS epidemic. Therefore, it is essential to pay greater attention to control and prevention programs for HIV/AIDS in these countries.

\section{Abbreviations}


SDGs: Sustainable Development Goals

UN: United Nation

UNAIDS: United Nations Program on HIV/AIDS

\section{Acknowledgements}

We would like to thank UNAIDS and World Bank database for provide data.

\section{Author contribution}

FKS, EA and SK designed the study. KM, SMH and SK processed the data. EA, MS and KM performed the statistical analysis. FKS, SK and KM interpreted the results. FKS, KM, SK and EA wrote the first draft. FKS, SK and EA revised the final draft. All authors read and approved the final manuscript. 


\section{References}

Akeroyd, A.V. (1994). HIV/AIDS in eastern and southern Africa. Review of African Political Economy 21, 173-184.

Arndt, C., and Lewis, J.D. (2000). The macro implications of HIV/AIDS in South Africa: a preliminary assessment. South African Journal of Economics 68, 380-392.

Ärnlöv, J. (2016). Estimates of global, regional, and national incidence, prevalence, and mortality of HIV, 1980-2015: the Global Burden of Disease Study 2015. The Lancet HIV 3, E361-E387.

Billebeau, G., Vodovar, N., Sadoune, M., Launay, J.M., Beauvais, F., and Cohen-Solal, A. (2017). Effects of a cardiac rehabilitation programme on plasma cardiac biomarkers in patients with chronic heart failure. European journal of preventive cardiology, 2047487317705488.

Boulogne, M., Sadoune, M., Launay, J., Baudet, M., Cohen-Solal, A., and Logeart, D. (2017). Inflammation versus mechanical stretch biomarkers over time in acutely decompensated heart failure with reduced ejection fraction. International Journal of Cardiology 226, 53-59.

Boutayeb, A. (2009). The impact of HIV/AIDS on human development in African countries. BMC Public Health 9, S3.

Colecraft, E. (2008). HIV/AIDS: nutritional implications and impact on human development. Proceedings of the Nutrition Society 67, 109-113.

De Cock, K.M., Mbori-Ngacha, D., and Marum, E. (2002). Shadow on the continent: public health and HIV/AIDS in Africa in the 21st century. The Lancet 360, 67-72.

de Freitas Souza, B.S., Silva, D.N., Carvalho, R.H., de Almeida Sampaio, G.L., Paredes, B.D., França, L.A., Azevedo, C.M., Vasconcelos, J.F., Meira, C.S., and Neto, P.C. (2017). Association of Cardiac Galectin-3 Expression, Myocarditis, and Fibrosis in Chronic Chagas Disease Cardiomyopathy. The American Journal of Pathology 187, 1134-1146.

Dorling D, S.M., Smith GD HIV and global health: global inequality of life expectancy due to AIDS. BMJ: British Medical Journal 2006;332:662-4 .

Gesesew, H.A., Mwanri, L., Ward, P., Woldemicahel, K., and Feyissa, G.T. (2016). Factors associated with discontinuation of anti-retroviral therapy among adults living with HIV/ AIDS in Ethiopia: a systematic review protocol. JBI Database of Systematic Reviews and Implementation Reports 14, 26-37.

HIV/AIDS, J.U.N.P.o. (2010). Global report: UNAIDS report on the global AIDS epidemic 2010 (UNAIDS).

Institute for Health Metrics and Evaluation (IHME) (2015). GBD Compare. Seattle, WA: IHME, University of Washington, 2015.

Ledwidge, M., Gallagher, J., Conlon, C., Tallon, E., O'Connell, E., Dawkins, I., Watson, C., O'Hanlon, R., Bermingham, M., and Patle, A. (2013). Natriuretic peptide-based screening and collaborative care for heart failure: the STOP-HF randomized trial. Jama 310, 66-74.

Lou, L.-X., Chen, Y., Yu, C.-H., Li, Y.-M., and Ye, J. (2014). National HIV/AIDS mortality, prevalence, and incidence rates are associated with the Human Development Index. American journal of infection control 42, 1044-1048. 
Murray, C.J., Vos, T., Lozano, R., Naghavi, M., Flaxman, A.D., Michaud, C., Ezzati, M., Shibuya, K., Salomon, J.A., and Abdalla, S. (2013). Disability-adjusted life years (DALYs) for 291 diseases and injuries in 21 regions, 1990-2010: a systematic analysis for the Global Burden of Disease Study 2010. The lancet 380, 2197-2223.

Piot, P., Greener, R., and Russell, S. (2007). Squaring the circle: AIDS, poverty, and human development. PLoS Med 4, e314.

UNADIS (2016). Fact sheet 2016 (http://www.unaids.org/en/resources/fact-sheet).

UNAIDS (2016a). Aids information: Data (http://aidsinfo.unaids.org/).

UNAIDS (2016b). How AIDS changed everything - MDG6: 15 years, 15 lessons of hope from the AIDS response (http://www.unaids.org/en/resources/documents/2015/ MDG6_15years-15lessonsfromtheAIDSresponse).

Whiteside, A. (2002). Poverty and HIV/AIDS in Africa. Third world quarterly 23, 313-332.

WHO (2016). Global Health Observatory (GHO) data(HIV/AIDS) (http://dx.doi.org/ 10.1080/01436590220126667).

Wong, P.C., Guo, J., and Zhang, A. (2017). The renal and cardiovascular effects of natriuretic peptides. Advances in physiology education 41, 179-185.

Yancy, C.W., Jessup, M., Bozkurt, B., Butler, J., Casey, D.E., Jr., Colvin, M.M., Drazner, M.H., Filippatos, G.S., Fonarow, G.C., Givertz, M.M., et al. (2017). 2017 ACC/AHA/HFSA Focused Update of the 2013 ACCF/AHA Guideline for the Management of Heart Failure: A Report of the American College of Cardiology/American Heart Association Task Force on Clinical Practice Guidelines and the Heart Failure Society of America. Journal of cardiac failure, 10.1016/j.cardfail.2017.1004.1014. 